\title{
A case of severe flood over Albania: a rainfall analysis from a satellite perspective
}

\author{
A. De Luque ${ }^{1}$, T. Porja ${ }^{2}$, A. Martín ${ }^{1}$, J. A. Guijarro ${ }^{3}$, and S. Alonso ${ }^{1}$ \\ ${ }^{1}$ Meteorology Group, Departament de Física, Universitat de les Illes Balears, Spain \\ ${ }^{2}$ Section of Meteorological Predictions, Department of Meteorology, Hydrometeorological Institute of Albania, Albania \\ ${ }^{3}$ Met. Centre at Balearic Islands, Instituto Nacional de Meteorología, Spain
}

Received: 28 October 2005 - Revised: 14 December 2005 - Accepted: 20 December 2005 - Published: 24 January 2006

\begin{abstract}
This paper presents results of daily rainfall estimates for the flood event in Albania occurred during the end of September 2002 (from the 21 until the 23). Estimated precipitations based on Meteosat-7 data and computed using various techniques, are compared with surface based observations. The two techniques, developed for convective clouds, were employed to screen the Albanian Flood. On one hand a single Infrared band technique known as Auto-estimator and on the other hand a three-channel Convective Rainfall Rate technique known as CRR. Secondly, for both methods, a number of corrections, such as, moisture, cloud growth rate, cloud top temperature gradient, parallax and orographic corrections were, also, performed and tested during the flood case. Preliminary results show that auto-estimator over-measure significantly daily rainfall with respect to the observed while CRR gives much closer rain quantities. The Auto-estimator power law curve was adjusted to the specific conditions using all the available rain rate gauge measurements. Satellite daily rainfall estimated by the two methods, corrected and calibrated were finally evaluated using the Albanian rain gauge network as ground true.
\end{abstract}

\section{Introduction}

Crucial aspects of heavy rainfalls in Mediterranean countries are the intensity with which they occur and their fatal consequences. They contribute generally to the seasonal torrent and river overflowing, causing severe floods that have great social, economic and landscaping impacts. The Albanian episode, occurred during the end of September, agrees closely with the previous aspects.

The development of visible and infrared techniques has a long history and relies upon the relationship between cloud-top characteristics and the rainfall falling from their

Correspondence to: A. De Luque

(angel.luque@uib.es) bases. From those techniques the Auto-estimator (Vicente et al,1998), computed in the Great Plains of central USA and areas adjacent to the Gulf of Mexico, estimated rainfall rates based on a non-linear, power-law regression relationship. The non-linear function, shown as Eq. (1), was calibrated using GOES $11 \mu \mathrm{m}$ band infrarred temperatures of the cloud top and collocated ground radar rainfall.

$R=1.1183 \cdot 10^{11} \cdot \exp \left(-3.6382 \cdot 10^{-2} \cdot T_{I R}^{1.2}\right)$

where $R$ is rainfall rate in $\mathrm{mm} \cdot \mathrm{h}^{-1}$ and $T_{I R}$ is the cloud top temperature in kelvin (K).

The Convective Rainfall Rate algorithm (CRR), based on the ideas of Kurino (1997), was developed by the SAF NWC (Satellite Application Facility on support to Nowcasting) project to detect intense mesoscale convective systems and to screen the most probable precipitation associated. It estimates rainfall intensity using the three bands of the Meteosat7 and fixed calibration matrices. Diurnal and nocturnal (Table 1) matrices used in this work were performed over the Iberian Peninsula, with ground radars and Meteosat-7 data as provided by the INM (Spanish Meteorological Institute) (INM, 2000). Observations from the three satellite bands are employed to extract rain rates from diurnal or nocturnal matrices in which, classes are transformed in rainfall intensity in $\mathrm{mm} \cdot \mathrm{h}^{-1}$ as shown in Table 2. Finally, CRR images are computed by drawing rainfall from matrices over every satellite pixel position.

Satellite rainfall corrections, such as moisture (PWRH), cloud growth rate (GR1) and cloud top temperature gradient (TGR) developed by Vicente et al. (1998) were used and tested in the present case. A dynamical version of the cloud growth rate correction (GR2) is applied as GR1 but taking in account the movement of clouds as follows: Virtual position of a cloudy point $30 \mathrm{~min}$ before was calculated using a grid of 15 by 15 pixels centred in the cloudy point. Moving the grid around the same point in the previous infrared image, correlation coefficients are calculated. The translation with higher correlation is then selected and the grid central points in both images are associated to apply the correction. 
Table 1. Section of the two dimensional or nocturnal matrix. During night hours Meteosat-7 images from the visible band are not available, this rainfall matrix was configured using only the two infrared channels. The vertical axis represents infrared $11 \mu \mathrm{m}$ satellite band temperatures $\left(T_{I R}\right)$ from $-66^{\circ} \mathrm{C}$ to $2^{\circ} \mathrm{C}$ every two degrees Celsius and the horizontal axis represents $T_{I R}-T_{W V}$ from $-11^{\circ} \mathrm{C}$ to $25^{\circ} \mathrm{C}$ every two degrees, where $T_{W V}$ are infrared temperatures from the satellite water vapour band. Matrices classes are transformed in rainfall intensity as shown in Table 2. To make easy the visual identification, highest rain classes are shaded.

\begin{tabular}{|c|c|c|c|c|c|c|c|c|c|}
\hline $\mathrm{Sp}-2 \mathrm{D}$ & -11 & -9 & -7 & -5 & -3 & -1 & 1 & 3 & 5 \\
\hline-66 & $\cdot$ & $\cdot$ & $\cdot$ & $\cdot$ & $\cdot$ & $\cdot$ & $\cdot$ & $\cdot$ & . \\
\hline-64 & . & 6 & 6 & 6 & . & . & . & . & • \\
\hline-62 & . & 6 & 5 & 5 & 5 & $\cdot$ & . & . & . \\
\hline-60 & . & 5 & 5 & 4 & 4 & 3 & . & $\cdot$ & . \\
\hline-58 & . & 5 & 5 & 4 & 4 & 4 & 4 & $\cdot$ & . \\
\hline-56 & . & $\cdot$ & 5 & 3 & 3 & 3 & 3 & $\cdot$ & . \\
\hline-54 & . & $\cdot$ & 0 & 3 & 3 & 3 & 3 & 0 & . \\
\hline-52 & · & $\cdot$ & 0 & 0 & 2 & 2 & 2 & 0 & . \\
\hline-50 & . & $\cdot$ & 0 & 0 & 0 & 0 & 0 & 0 & 0 \\
\hline-48 & . & $\cdot$ & $\cdot$ & 0 & 0 & 0 & 0 & 0 & 0 \\
\hline-46 & . & $\cdot$ & $\cdot$ & 3 & 3 & 0 & 0 & 0 & 0 \\
\hline-44 & . & $\cdot$ & $\cdot$ & $\cdot$ & 2 & 2 & 0 & 0 & 0 \\
\hline-42 & . & $\cdot$ & $\cdot$ & $\cdot$ & 0 & 1 & 0 & 0 & 0 \\
\hline-40 & . & $\cdot$ & $\cdot$ & $\cdot$ & $\cdot$ & 1 & 0 & 0 & 0 \\
\hline-38 & . & $\cdot$ & $\cdot$ & $\cdot$ & $\cdot$ & 0 & 0 & 0 & 0 \\
\hline-36 & $\cdot$ & $\cdot$ & $\cdot$ & $\cdot$ & $\cdot$ & $\cdot$ & 0 & 0 & 0 \\
\hline-34 & . & $\cdot$ & $\cdot$ & $\cdot$ & $\cdot$ & $\cdot$ & 4 & 0 & 0 \\
\hline-32 & . & $\cdot$ & $\cdot$ & $\cdot$ & $\cdot$ & $\cdot$ & . & 3 & 0 \\
\hline
\end{tabular}

Table 2. Relationship between rainfall intensities in $\mathrm{mm} \cdot \mathrm{h}^{-1}$ and matrices classes used by the CRR algorithm.

\begin{tabular}{cc}
\hline Rainfall intensity $\left(\mathrm{mm} \cdot \mathrm{h}^{-1}\right)$ & Rainfall matrices Classes \\
\hline No data & 0 \\
0 & 1 \\
1 & 2 \\
2 & 3 \\
3 & 4 \\
5 & 5 \\
7 & 6 \\
10 & 7 \\
15 & 8 \\
20 & 9 \\
30 & 10 \\
\hline 50 & 10 \\
\hline
\end{tabular}

Parallax (PC) and orographic corrections (OC) were performed following instructions given by Vicente in latest publications (Vicente et al., 2002). The MM5 Numerical Model with analysis grids from the European Centre for Medium Range Weather Forecast (ECMWF) was used to monitor the meteorological evolution of the flood case and to generate the precipitable water $(\mathrm{PW})$ and relative humidity $(\mathrm{RH})$ fields to compute the moisture correction factor (PWRH) and the $850 \mathrm{hPa}$ wind vector fields to calculate the orographic correction factor $(\mathrm{OC})$.

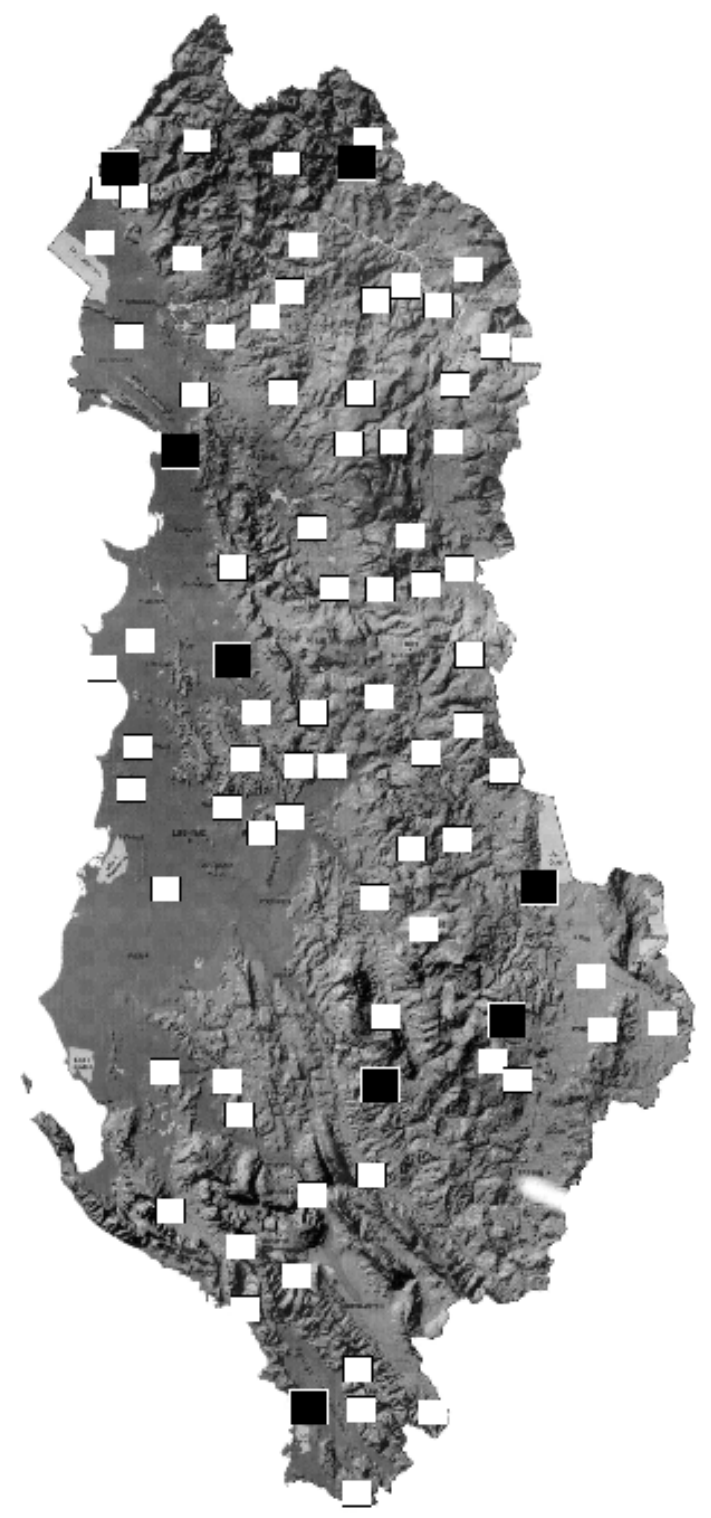

Fig. 1. Albanian physical surface and meteorological stations. White boxes represent daily rainfall measurements and black boxes daily and rainfall intensities. The territory is very irregular in general, but the highest mountains, above to $2300 \mathrm{~m}$, are found in the north and in the south of the country.

\section{Data and case of study}

The Meteosat-7 datasets employed in the present work are: $11 \mu \mathrm{m}$ infrared band brightness temperature in kelvin $(\mathrm{K})$ $T_{I R}$, infrared water vapour band in kelvin $T_{W V}(\mathrm{~K})$ and the visible channel in brightness counts. The Meteosat data are contained in images from EUMETSAT and supplied by the INM, which cover Europe every 30 min with a pixel spatial resolution over Albania around 7 by $7 \mathrm{~km}$. The period of the satellite dataset used in this study are from 00:00 UTC of September 21 to 23:30 UTC of 23 September.

Ground rainfall intensities in $\mathrm{mm} \cdot \mathrm{h}^{-1}$ recorded by 8 stations, every hour from 06:00 to 23:00 UTC at 22 September 
2002 (see black boxes in Fig. 1) and daily rainfall accumulations recorded by 81 stations over Albania at 21, 22 and 23 September 2002 (see white and black boxes in Fig. 1).

The month of September 2002 was characterized by unstable weather with precipitations that covered all the Albanian territory. The most critical days were the 21 to 26 of September, specially the day 22 , which achieved more than $180 \mathrm{~mm}$ in just $24 \mathrm{~h}$ in many locations in the north of the country. The rain began at 21 September and reached its highest intensity at 22 September (at 18.00 UTC) but the next days, they were not as dangerous as this one (Fig. 2). The MM5 numerical model does not reproduce any intense cyclone or active front for the days 21 and 22 over Albania. For this period the simulation shows a persistent south-western low level jet that supplied moist Mediterranean air at low levels over the region, which combined with the role of the orography as convection triggering mechanism, increased the instability of the environment over Albania. During the day 23 the numerical model shows a cyclone approaching to Albania from the north-west with an associated cold front that caused precipitations.

\section{Methodology}

The two original satellite rainfall techniques, A-E and CRR, are used to compute, firstly rainfall intensity in $\mathrm{mm} \cdot \mathrm{h}^{-1}$ and secondly, daily rainfall in $\mathrm{mm}$ for each of the three days (Fig. 3). The daily rainfall measurements of 81 stations were spatially interpolated, and later, remapped to satellite projection and resolution for each day (Fig. 2). Observed and Estimated daily rainfall fields are compared in a qualitative and quantitative manner. For the quantitative verification common statistical indices, such as, bias (BIAS), root mean quadratic errors (RMS) and correlation coefficients (CORR) were performed over the areas covered with observed rain.

The A-E in its original form over-measures daily rainfall in the three days of the case of study (see BIAS in Table 3 and Fig. 3a to c). In addition, corrections do not solve the high-bias problem, as can be seen in Table 3. The calibration procedure tries to adjust the A-E power law relation to the reality of the rainfall case by computing a new A-E power law relation using the rainfall intensities available from $8 \mathrm{Al}$ banian stations (see black boxes in Fig. 1). The method is based on the selection of fully convective ground-based rainfall rates and associate them with satellite infrared brightness temperature pixels $\left(T_{I R}\right)$. In Fig. $4 \mathrm{a}$ it is plotted the natural logarithm of rainfall points versus $T_{I R}$. As can be seen, the distribution of points is nearly linear and a linear regression fit can be applied obtaining $\ln (2)$. In Fig. 4a is also shown the logarithmic-transformed original A-E Eq. (1) as $\ln (1)$. By inverting the $\ln (2)$ equation, an improved power law relation is obtained and shown as follow.

$R^{*}=3.42605 \cdot 10^{14} \cdot \exp \left(-0.15259 \cdot T_{I R}\right)$

$R^{*}$ is, also, the rainfall rate in $\mathrm{mm} \cdot \mathrm{h}^{-1}$ and $T_{I R}$ is the cloud top temperature in kelvin $(\mathrm{K})$. Images generated using the
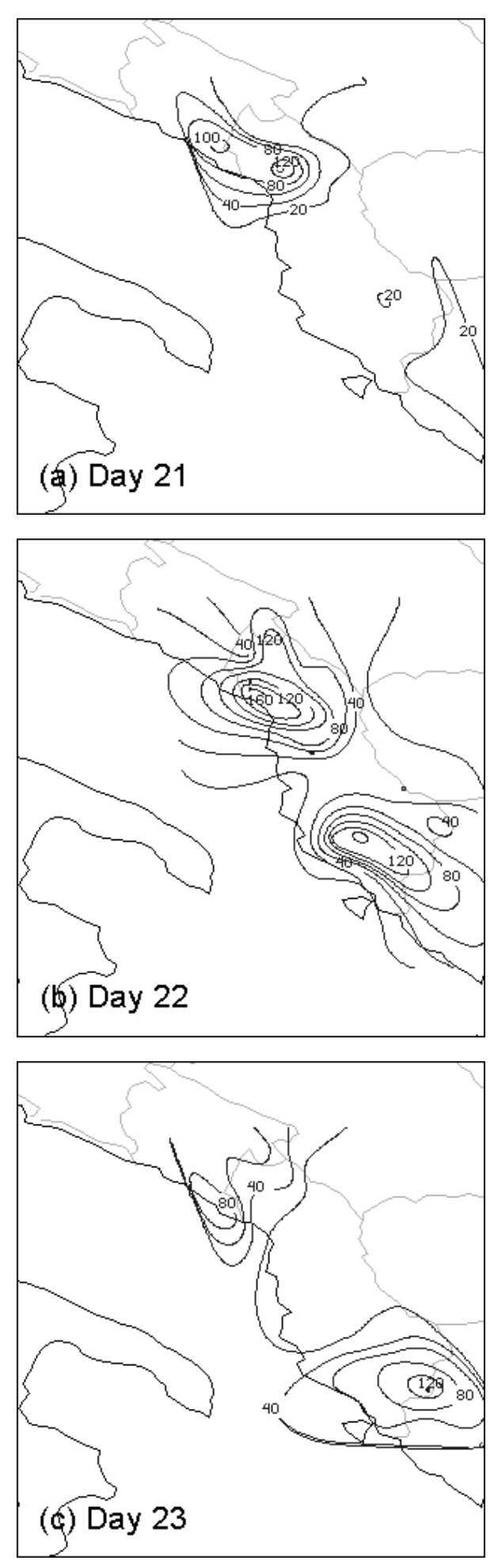

Fig. 2. Daily observed rainfall in $\mathrm{mm}$ for each of the three days. The data of the 81 stations, after being spatially interpolated, they were remapped to satellite projection and resolution for the three days of the flood case.

new power law relation and plotted in Fig. $4 \mathrm{~b}$ are called A-E cal in the present study. 
Table 3. Results using A-E original power-law relation (1) daily rainfall and correction factors. Mean, SD (Standard deviation), BIAS and RMS (root mean quadratic error) are in mm. CORR (correlation coefficient) Boldfaced numbers show best statistical result in every line.

\begin{tabular}{cccccccccc}
\hline & OBS & A-E & +PWRH & +GR1 & +GR2 & +TGR & +PC & +OC & Days \\
\hline Sample Size & & & & & 6699 & & & & \\
Mean & 35.37 & 172.84 & 159.66 & 113.92 & 106.19 & 101.77 & 179.97 & 203.86 & \\
SD & 33.46 & 215.31 & 206.76 & 141.69 & 146.59 & $\mathbf{1 2 5 . 1 1}$ & 216.65 & 255.73 & 21,22 \\
BIAS & & -137.47 & -124.29 & -78.55 & -70.82 & $-\mathbf{6 6 . 4 0}$ & -144.60 & -168.49 & 23 \\
RMS & & 246.49 & $\mathbf{2 3 1 . 4 7}$ & 153.55 & 153.49 & 133.51 & 250.00 & 296.41 & \\
CORR & & 0.39 & 0.42 & 0.40 & 0.41 & 0.40 & $\mathbf{0 . 4 5}$ & 0.41 &
\end{tabular}

Table 4. Results using A-E calibrated relation (2) daily rainfall and correction factors.

\begin{tabular}{cccccccccc}
\hline & OBS & A-E cal & +PWRH & +GR1 & +GR2 & +TGR & +PC & +OC & Days \\
\hline Sample Size & & & & & 6699 & & & & \\
Mean & 35.37 & 30.49 & 38.34 & 20.49 & 19.61 & 18.33 & 31.73 & 38.82 & \\
SD & 33.46 & 41.05 & 58.78 & 27.45 & 28.93 & $\mathbf{2 4 . 5 1}$ & 41.26 & 57.14 & 21,22, \\
BIAS & & 4.88 & $\mathbf{- 2 . 9 7}$ & 14.69 & 15.76 & 17.05 & 3.64 & -3.45 & 23 \\
RMS & & 41.81 & 55.64 & $\mathbf{3 6 . 7 5}$ & 37.54 & $\mathbf{3 6 . 7 5}$ & 39.77 & 53.24 & \\
CORR & & 0.39 & 0.37 & 0.40 & 0.41 & 0.40 & $\mathbf{0 . 4 5}$ & 0.41 & \\
\hline
\end{tabular}

Table 5. Results using CRR daily rainfall and correction factors.

\begin{tabular}{cccccccccc}
\hline & OBS & CRR & +PWRH & +GR1 & +GR2 & +TGR & +PC & +OC & Days \\
\hline Sample Size & & & & & 6699 & & & & \\
Mean & 35.37 & 37.43 & 50.00 & 23.07 & 21.76 & 21.16 & 39.31 & 46.92 & \\
SD & 33.46 & 45.95 & 67.31 & 28.30 & 28.44 & $\mathbf{2 5 . 6 3}$ & 46.49 & 61.43 & 21,22, \\
BIAS & & $\mathbf{- 2 . 0 6}$ & -14.63 & 12.30 & 13.61 & 14.21 & -3.94 & -11.55 & 23 \\
RMS & & 45.71 & 65.37 & 37.25 & 36.81 & $\mathbf{3 6 . 3 1}$ & 44.66 & 58.47 & \\
CORR & & 0.37 & 0.35 & 0.36 & 0.40 & 0.39 & $\mathbf{0 . 4 2}$ & 0.39 & \\
\hline
\end{tabular}

Table 6. Corrections one behind other in a chain combination applied over A-E cal and CRR.

\begin{tabular}{|c|c|c|c|c|c|c|}
\hline & OBS & $+\mathrm{GR} 2+\mathrm{PC}+\mathrm{OC}$ & $\begin{array}{l}\text { A-E cal } \\
\quad+\mathrm{GR} 2+\mathrm{PC}+\mathrm{OC}+\mathrm{PWRH}\end{array}$ & $+\mathrm{GR} 2+\mathrm{PC}+\mathrm{OC}$ & $\begin{array}{l}\mathrm{CRR} \\
+\mathrm{GR} 2+\mathrm{PC}+\mathrm{OC}+\mathrm{PWRH}\end{array}$ & Days \\
\hline Sample Size & \multicolumn{6}{|c|}{6699} \\
\hline Mean & 35.37 & 25.76 & 26.08 & 29.03 & 39.38 & \\
\hline SD & 33.46 & 41.36 & 42.08 & 39.93 & 58.88 & 21,22 , \\
\hline BIAS & & 9.61 & 8.65 & 6.34 & -4.01 & 23 \\
\hline RMS & & 40.42 & 40.89 & 39.58 & 54.04 & \\
\hline CORR & & 0.47 & 0.46 & 0.44 & 0.43 & \\
\hline
\end{tabular}

\section{Results and conclusions}

While auto-estimator over-estimates significantly daily rainfall with respect to the observed CRR gives much closer rain quantities (see BIAS in Tables 3 and 5 and Figs. 3d to f). This result suggests that $\mathrm{CRR}$ are more stable than original $\mathrm{A}-\mathrm{E}$ in estimating daily rainfall because a calibration of CRR matrices was not necessary in the present case of study. Although correlation coefficients comparing CRR daily precipitation to observed are slightly lower than comparing A-E to observed (see CORR values in Table 5).

Calibrated A-E power law regression curve computed for this case using Eq. (2) diminished daily rainfall at least five times with respect the original curve developed for the great plains in USA by Vicente et al. (1998) (see BIAS in Tables 3 and 4 and Figs. $3 a$ to $\mathrm{c}$ and 5 ).

calibrated A-E and CRR algorithms over-estimate daily precipitation area but under-estimate maximum rainfall 


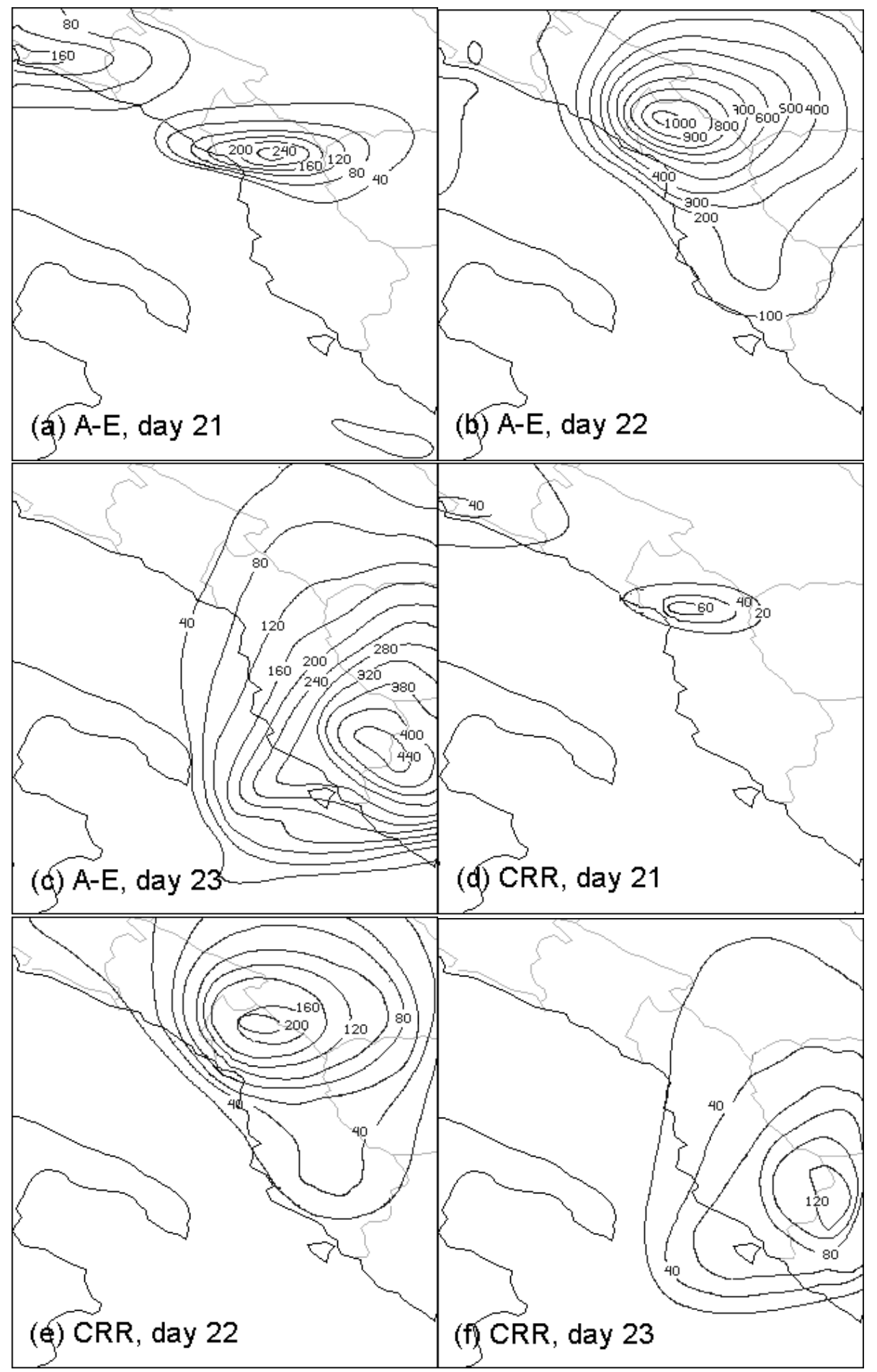

Fig. 3. Auto-Estimator (A-E) and CRR daily rainfall in mm performed for every day of the flood case.

quantities with respect to the observed daily rainfall (see Figs. 3d to $\mathrm{f}$ for CRR and Figs. 5a to c for A-E cal). On the other hand, two observed daily maximums, one around $150 \mathrm{~mm}$ on the south of the country the day 22 and the other, during the day 23 , of $85 \mathrm{~mm}$, over the north, are not detected by satellite algorithms.
Sensibility test of correction factors for this flood case demonstrated, that parallax (PC), dynamic growth rate (GR2) and orographic correction (OC) can improve the delineation of satellite daily rainfall areas with respect to the observed (see CORR values in Tables 3 to 5). On the other hand recalibration affects, overall, the rainfall amounts and it can reduce 

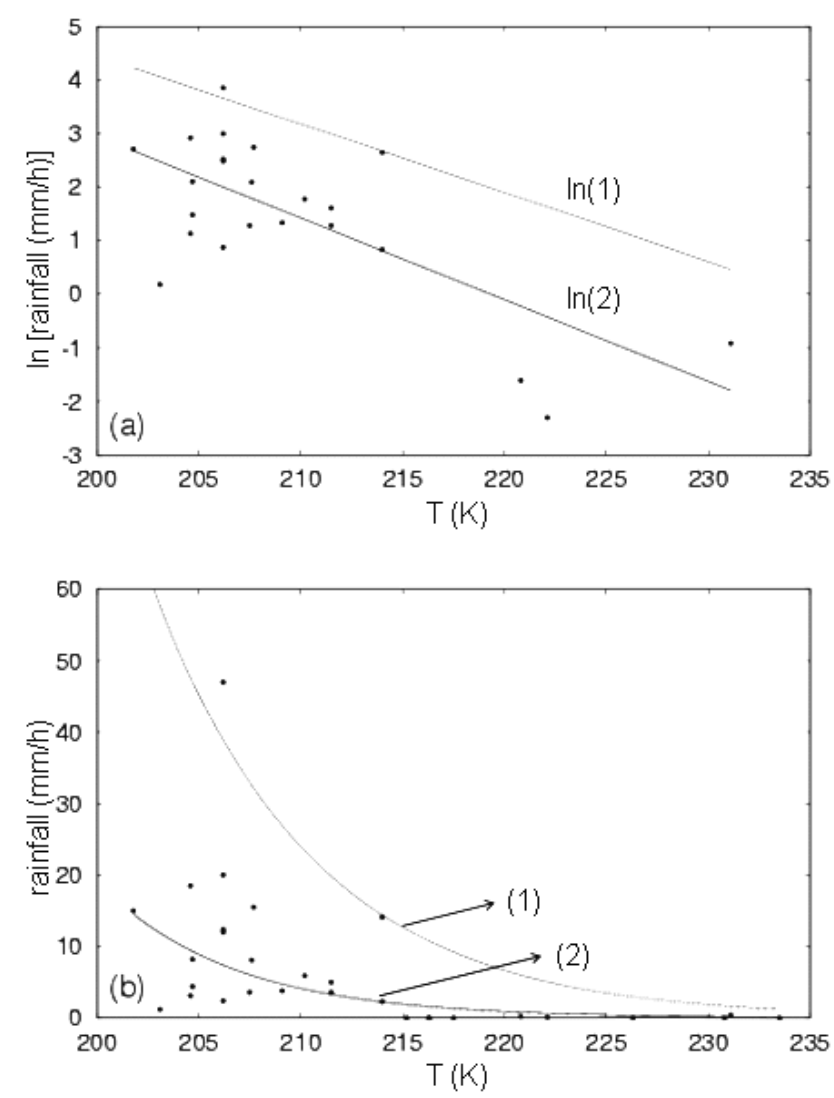

Fig. 4. (a) natural logarithm of rainfall intensity points versus $11 \mu \mathrm{m}$ brightness temperature. $\ln (1)$ and $\ln (2)$ are the natural $\log$ arithms of Eq. (1) and (2) respectively. (b) rainfall intensity in $\mathrm{mm} \cdot \mathrm{h}^{-1}$ versus $11 \mu \mathrm{m}$ brightness temperature. Equation (1) corresponds to the original Auto-Estimator (A-E) power-law curve and (2) corresponds to the calibrated curve (A-E cal).

the BIAS and RMS (see Table 4). The PC moves slightly the daily rainfall to the south-west (see Fig. 6a), GR2 diminished the daily rainfall because this correction put to cero the rain rate for the points in which the cloud brightness temperature is increasing with time (see Fig. 6b) and OC increases the daily rainfall on the windward side and tops of the highest mountains (see Fig. 6c).

The corrections with best results can work one after another in a chain combination in order to increase correlation coefficients and to adjust satellite daily rainfall estimations to those measured on the ground (see statistics in Table 6 and Figs. 6d to f).

Acknowledgements. To the Spanish Meteorological Institute (INM) for the Meteosat-7 data. To the SAFNWC members of the INM for the Meteosat-7 CRR matrices. To the Hydrometeorological Institute of Albania for the pluviographic data and closest collaboration.

Edited by: V. Kotroni and K. Lagouvardos Reviewed by: anonymous referee
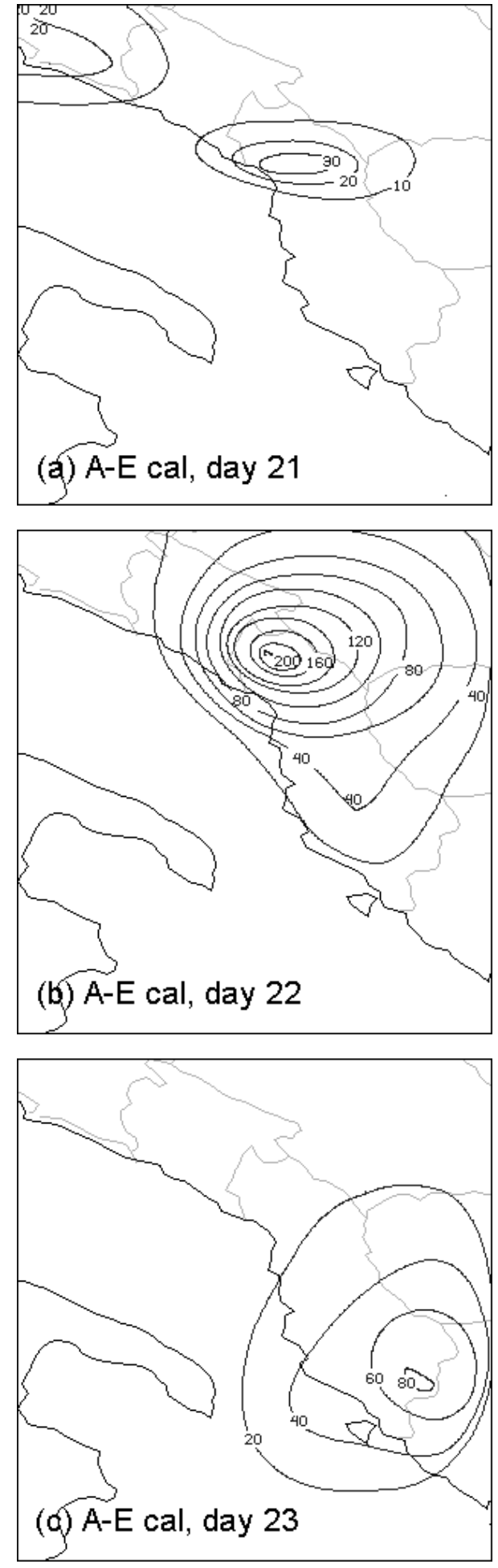

Fig. 5. Daily rainfall using the infrared curve (2). 

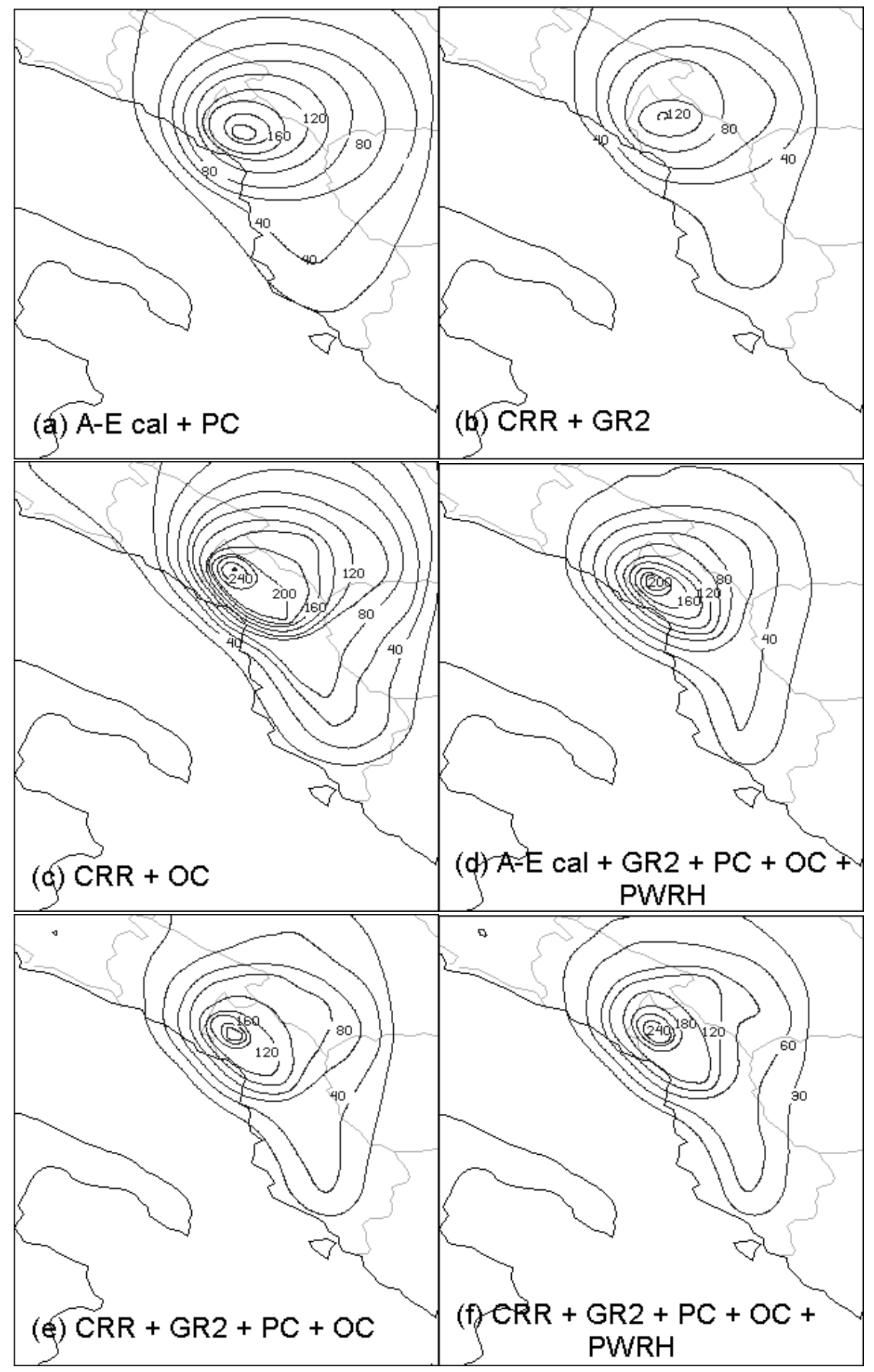

Fig. 6. Daily precipitation for the day 22 computed using A-E cal and CRR algorithms and then corrected by different factors. (a) A-E cal corrected by parallax (PC). (b) CRR corrected by the dynamic growth rate factor (GR2). (c) CRR corrected by the orographic factor (OC). (d) to (f), the best corrections for this case of study are selected to work one after another in a chain combination in order to improve the results (see Table 6). 


\section{References}

INM: Scientific Report for MTR on PGE05: Convective Rainfall Rate, EUMETSAT Technical \& Scientific Documentation (SAF/NWC/INM/SCI/MTR/001), 2000.

Kurino, T.: A Rainfall Estimation with the GMS-5 Infrared Splid Window and Water Vapor Measurements, Tech. Rep., Meteorological Satellite Centre, Japan Meteorological Agency, 1997.
Vicente, G. A., Davenport, J. C., and Scofield, R. A.: The role of orographic and parallax corrections on real time high resolution satellite rainfall rate distribution, Int. J. Rem. Sens., 23, 221-230, 2002.

Vicente, G. A., Scofield, R. A., and Menzel, W. P.: The operational GOES infrared rainfall estimation technique, Bull. Amer. Meteor. Soc., 79, 1883-1898, 1998. 